\title{
Preparation, Characterization and In vitro Evaluation of Theophylline Nanoparticles Prepared with Dextran- Conjugated Soy Protein
}

\author{
Bei Jin ${ }^{1,2 *}$, Xiaosong Zhou ${ }^{1}$, Caiyan Chen ${ }^{1}$, Xiaosa Zhang ${ }^{1}$ and Siqiao Chen ${ }^{1}$ \\ ${ }^{1}$ School of Chemistry and Chemical Engineering, Lingnan Normal University, Zhanjiang 524048, ${ }^{2}$ Engineering Research Center \\ of Starch and Vegetable Protein Processing, Ministry of Education, South China University of Technology, Guangzhou 510640, \\ China
}

*For correspondence: Email: jinbeikim2013@163.com; Tel/Fax: +86-759-3174025

\begin{abstract}
Purpose: To design and characterize theophylline nanoparticles synthesized with dextran-conjugated soy protein isolate (SPI), and evaluate their encapsulation capacity and release profile in simulated gastrointestinal media.

Methods: SPI-based nanoparticles were prepared with soy protein-dextran conjugates obtained by titanium dioxide (TiO2) photocatalysis using a simple ionic gelation method. Formation of the conjugates was monitored spectrophotometrically for free amino group content $\left(A_{340 \mathrm{~nm}}\right)$ and by Fourier transform infrared spectroscopy (FT-IR). The particles were characterized by for particle size and morphology, zeta potential, and in vitro release.

Results: Successful glycoconjugation was evidenced by changes in ultraviolet (UV) absorption $\left(A_{294}\right)$, browning, free amino group and FT-IR spectra. The particle size and zeta potential of SPI-dextran nanoparticles tended to increase and decrease, respectively, with increasing SPI/dextran mass ratio. Maximum encapsulation and loading efficiencies were around 91.6 and $3.08 \%$, respectively, which were significantly higher than for SPI nanoparticles. Successful encapsulation of theophylline in the polymeric matrix was confirmed by FT-IR spectra. In addition, SPI-dextran nanoparticles reduced release $(p<0.05)$ of theophylline in simulated gastric fluid but and enhanced release $(p<0.05)$ under simulated intestinal condition.

Conclusion: These results suggest that SPI-dextran nanoparticle formulation is an attractive approach to achieve encapsulation and controlled release of bioactive substances.
\end{abstract}

Keywords: Soy protein, Dextran, Nanoparticles, Encapsulation, Controlled release, Theophylline

Tropical Journal of Pharmaceutical Research is indexed by Science Citation Index (SciSearch), Scopus, International Pharmaceutical Abstract, Chemical Abstracts, Embase, Index Copernicus, EBSCO, African Index Medicus, JournalSeek, Journal Citation Reports/Science Edition, Directory of Open Access Journals (DOAJ), African Journal Online, Bioline International, Open-J-Gate and Pharmacy Abstracts

\section{INTRODUCTION}

For years now, controlled delivery of bioactive agents has remained a major focus of pharmaceutical formulation research due to their relative permeability, robustness and short recovery after stress or damage that are related to mucous membrane [1]. The typical controlled delivery system shows a pattern of bioactive release, in which the bioactive concentration is maintained in the therapeutic window for a long enough period of time, thereby ensuring sustained physiological benefits.

Biopolymer-based nanoparticles have gained potential application in the field of targeted/controlled drug and nutraceuticals delivery $[2,3]$. Their subcellular size provides 
several advantages such as prolonged gastrointestinal residence, better tissue penetration, and superior cellular uptake [4]. Besides, these nanoparticles exhibit lower cytotoxicity and higher degradability [5]. All of these features make them an attractive candidate as an efficacy enhancer for the functional foods. Protein-based nanoparticles have been studied extensively as a delivery vehicle because they interact well with both the drug and solvent or nutraceuticals [2].

Soy protein isolate (SPI) has been used to develop nano-scaled delivery systems for its natural abundance, desirable water solubility, and balanced amino acid profile that facilitates the protein-nutraceutical interaction [6]. Soy protein also has many functional groups such as carboxyl and amide/amine groups, which can be modified to different extents by existing methods to change its interactions with other natural materials, thus leading to nanoparticles synthesized with SPI and polysaccharides using different methods $[7,8]$. Among these different methods, cold gelation could develop the smaller size of these particles in the range of 10 to 1,000 $\mathrm{nm}$ with desirable stability. Dextran is well known for its degradability by dextranase, biocompatibility and non-toxicity. Nanoparticles were obtained from dextran modified with epoxides [9] and fatty acid esters [10]. However, to the best of our knowledge, there has been no systematic report by now on the fabrication of nanoparticles with SPI-dextran conjugates.

There is a growing scientific interest in the influence of photocatalysis on synthesis of compounds with improved properties. Photocatalysis provides a green chemical route for organic functional group transformation under mild conditions. In the past two decades, it has been successfully applied to organic synthesis such as hydroxylation of aromatic, oxidation of amine and carbonylation [11-13]. However, reports on the synthesis and evaluation of SPIglycoconjugates obtained by $\mathrm{TiO}_{2}$ photocatalysis are scarce.

The aim of this study was to explore, in-depth, the application of the nanoparticles synthesized with dextran conjugated soy protein by $\mathrm{TiO}_{2}$ photocatalysis treatment as a carrier for theophylline. Theophylline was chosen as the model drug due to its low molecular mass and partial water-solubility and little interaction with soy protein [14].

\section{EXPERIMENTAL}

\section{Materials}

Dextran (MW: 60,000-90,000) were purchased from Chanshou Biological Co. Ltd (Jiashu Province, China). SPI was obtained from Wonderful Tech. Co. (Shandong Province, China), containing (on dry basis) $6.5 \%$ moisture, $1.0 \%$ ash, $0.2 \%$ lipid, $90.2 \%$ protein (determined by Kjeldahl method, $\mathrm{N} \times 6.25$ ). Theophylline (99.98\% purity), pepsin (from porcine stomach; 3200 units/mg of proteins), pancreatin (from porcine pancreas; meeting USP specifications) were purchased from Sigma Chemical Co. (St Louis, MO, USA). Calcium chloride and all other reagents were of analytical grade.

\section{Preparation of SPI-dextran conjugate}

SPI and dextran samples were prepared as follows: SPI were mixed with dextran according to certain mass ratio, and then dissolved in 20 $\mathrm{mM}$ potassium phosphate buffer $\mathrm{pH}$ 8. The solution was ready for the photocatalytic reaction tests. The soy protein-dextran solution was treated at photocatalytic power of $1000 \mathrm{~W}$ for $2 \mathrm{~h}$. For each test, $20 \mathrm{~mL}$ SPI-dextran solution was placed in a $50 \mathrm{~mL}$ jacketed vessel with a constant flow of $4 \pm 2{ }^{\circ} \mathrm{C}$ circulation water at a rate of $0.6 \mathrm{~L} / \mathrm{min}$ to maintain a sample temperature below $40{ }^{\circ} \mathrm{C}$. A digital thermometer was used to detect the sample temperature. All tests were carried out in triplicate. The photocatalytic Maillard reaction was conducted in a $50 \mathrm{ml}$ cylindrical glass vessel fixed in a XPA-II photochemical reactor (Nanjing Xujiang Machineelectronic Plant). The filter system comprises a house-made filter mounted on the lamp to eliminate infrared irradiation and a UV filter which can absorb the light with wavelength less than $400 \mathrm{~nm}$.

\section{Determination of free amino group contents}

OPA assay was used to analyse the graft degree of SPI by calculating the decrease of the free amino groups in the protein after glycation. The OPA reagent was prepared according to Caillard et al [15]. OPA ( $80 \mathrm{mg}$, dissolved in $2 \mathrm{ml} 95 \%$ ethanol), $50 \mathrm{ml} 0.1 \mathrm{M}$ sodium tetraborate buffer solution at pH 9.5, $5 \mathrm{ml} 20 \% \mathrm{SDS}$, and $0.2 \mathrm{ml} 2-$ mercaptoethanol were mixed together and the mixture was then diluted with water to $100 \mathrm{ml}$. The OPA reagent was prepared freshly before use. The treated SPI-dextran copolymer $(50 \mu \mathrm{l}$, 10-fold dilution) was mixed with $1 \mathrm{ml}$ OPA reagent. After being shaken and laid in the dark 
at room temperature for $2 \mathrm{~min}$, the absorption at $340 \mathrm{~nm}$ was measured immediately.

\section{Preparation of blank and theophylline-loaded SPI/dextran nanoparticles}

Nanoparticles were formed with freshly prepared SPI or SPI-dextran conjugate using an ionic gelation method [16] with slight modifications. SPI or SPI-dextran was dissolved in deionized water at a concentration of $1 \mathrm{mg} / \mathrm{mL}$. The mass ratio of SPI and dextran in the mixed dispersion was set at 2:1, 1:1 and 1:2, while the total polymer concentration was fixed at $1 \mathrm{mg} / \mathrm{mL}$. Mild stirring was applied throughout the mixing process to avoid precipitation. To initiate the formation of nanoparticles, $4 \mathrm{~mL}$ of $\mathrm{CaCl}_{2}$ solution was added dropwise to the above mentioned mixture, and the resulting dispersion was stirred vigorously for $1 \mathrm{~h}$. The final concentration of SPI or SPI-dextran conjugate in the suspension was $0.36 \mathrm{mg} / \mathrm{mL}$, while the content of $\mathrm{CaCl}_{2}$ ranged from 0.1 to $1.6 \mathrm{mg} / \mathrm{mL}$.

To prepare theophylline-encapsulated nanoparticles, theophylline solution $(10 \mathrm{mg} / \mathrm{mL}$ in deionized water) was added dropwise to the resulting solution to achieve a polymer : theophylline mass ratio of 10:1 (w/w). The formed nanoparticles were purified by centrifugation at $10,000 \mathrm{~g}$ for $20 \mathrm{~min}$, redispersed in deionised water at the same concentration and then freeze dried.

\section{Determination of particle size and zeta potential}

Both SPI and SPI-dextran nanoparticle dispersions were subjected to the following measurements. The size and zeta-potential of the nanoparticles were measured at $25{ }^{\circ} \mathrm{C}$ respectively by dynamic light scattering and laser Doppler velocimetry using a Zetasizer NanoS (model ZEN1600, Malvern Instruments Ltd., UK). Their suspensions were diluted in $0.02 \mathrm{M}$ phosphate buffer (pH 8.0) to suitable concentration before analysis.

\section{Scanning electron microscopy}

Lyophilized SPI and SPI-dextran nanoparticles were fractured and attached to the SEM aluminum sample plate through the double-sided conductive carbon tabs. SEM observation was performed using a TM-3000 scanning electron microscope (Hitachi, Japan) in the charge-up reduction mode at an accelerating voltage of 15 $\mathrm{kV}$.
Determination of encapsulation (EE) and loading efficiency (LE)

The EE of theophylline-loaded nanoparticles was determined as previously reported [17]. Ten milligrams of the freeze-dried nanoparticles was washed with approximately $5 \mathrm{~mL}$ deionized water, and the suspension was filtrated through a Whatman No. 1 filter paper. The filtrate was subjected to spectrophotometric measurement at $272 \mathrm{~nm}$ with a Spectrumlab 22PC spectrophotometer (Shanghai Lengguang Technology Co. Ltd., Shanghai, China). This procedure was repeated for three times until the last filtrate did not exhibit any absorbance. Then all the filtrates were combined and measured again for its absorbance at $272 \mathrm{~nm}$, which was converted to the content of free theophylline using an established calibration curve $\left(R^{2}=\right.$ 0.9997). The powder (nanoparticles) remained after the filtration was dried under reduced pressure and weighed. The EE and LE of the samples were calculated as in Eqs 1 and 2.

$E E(\%)=100-(W f / W t) 100$

where $\mathrm{Wf}$ and $\mathrm{Wt}$ are the weight of free and encapsulated theophylline, respectively.

$\operatorname{LE}(\%)=\{(\mathrm{Wt}-\mathrm{Wf}) / \mathrm{Wn}\} 100$

where $\mathrm{Wt}$ and $\mathrm{Wf}$ are as defined for Eq 1, and $\mathrm{Wn}$ is the weight of the nanoparticles.

\section{Theophylline release studies}

After lyophilization, the theophylline-loaded nanoparticles were washed with deionized water as discussed above. Ten milligrams of the resulting powder was dispersed in $20 \mathrm{~mL}$ of simulated gastric fluid containing $1 \mathrm{mg} / \mathrm{mL}$ pepsin, $2.0 \mathrm{~g}$ of sodium chloride, $7.0 \mathrm{~mL}$ of $37 \%$ hydrochloric acid and $1000 \mathrm{~mL}$ of double-distilled water. The suspension was incubated at $37^{\circ} \mathrm{C}$ in a water bath for $2 \mathrm{~h}$, after which the mixture was heated at $100{ }^{\circ} \mathrm{C}$ for $5 \mathrm{~min}$ to deactivate pepsin. After a centrifugation performed at $10,000 \mathrm{~g}$ and $4{ }^{\circ} \mathrm{C}$ for $20 \mathrm{~min}$, the supernatant containing the released theophylline was collected and freezedried, while the precipitate was re-dispersed in $20 \mathrm{~mL}$ of simulated intestinal fluid containing 10 $\mathrm{mg} / \mathrm{mL}$ pancreatin, $6.8 \mathrm{~g}$ of monobasic potassium phosphate, $190 \mathrm{~mL}$ of $0.2 \mathrm{~N}$ sodium hydroxide and $600 \mathrm{~mL}$ of double-distilled water. The dispersion was incubated for $2 \mathrm{~h}$, and heated to deactivate pancreatin.

A second centrifugation was carried out. The supernatant was freeze-dried, while the precipitate was discarded. The powder yielded 
after lyophilization was suspended in deionized water and extracted under vigorous stirring for 10 $\min$. The suspension was then filtered again and measured for its absorbance at $272 \mathrm{~nm}$, which was converted to the content of released theophylline.

Theophylline release $(\%)=(\mathrm{Tr} / \mathrm{Tt}) 100$

where $\mathrm{Tr}$ and $\mathrm{Tt}$ are the amount of theophylline released and total theophylline content of the nanoparticles, respectively.

\section{FT-IR study of the nanoparticles}

Both the blank and theophylline-incorporated nanoparticles were analyzed for their infrared spectra. All samples were obtained by an FT-IR spectrometer (Nicolet Nexus 470, DTGS). Diffusive reflectance of the IR was measured using the powder specimens diluted with potassium bromide $(\mathrm{KBr})$ powder of spectroscopic grade by one-tenth and recorded with an average of 32 scans at a resolution of 4 $\mathrm{cm}^{-1}$. Background noise was corrected with pure $\mathrm{KBr}$ data.

\section{Statistical analysis}

All measurements were performed in triplicate. The results obtained are presented as mean \pm standard error of the mean (SEM). Data were processed by analysis of variance using the
Origin 7.5 software (Origin Lab Corp., MA, USA), and $p<0.05$ was considered statistical significant.

\section{RESULTS}

\section{Conjugation of dextran on SPI}

Effect of $\mathrm{TiO}_{2}$ photocatalysis treatment on UV absorbance and browning are shown in Fig 1. The formation of SPI-dextran glyconjugates through $\mathrm{TiO}_{2}$ photocatalysis was confirmed by increase in UV absorbance of solutions (Fig 1). The $\mathrm{A}_{294}$ of SPI-dextran solutions increased from approximately 0.28 to 0.86 ; in the case of $A_{420}$, it increased from approximately 0 to 0.24 .

Fig 2 showed that the content of free amino groups of FA-SPI as a function of mixing ratio. As the SPI/dextran ratio changed from 1:2 to $2: 1$, the content of free group was decreased by 12 $\%$. The data further confirmed that dextran was conjugated to SPI via a chemical linkage to the free amino groups. From the results, it is obvious that the decrease in free amino group was in accordance with the increase in browning at 420 $\mathrm{nm}$ (Fig. 1), which was in accordance with Zhang et al [18] who reported the extent of glycation in soy $\beta$-conglycinin-dextran model system was enhanced during the Maillard reaction.

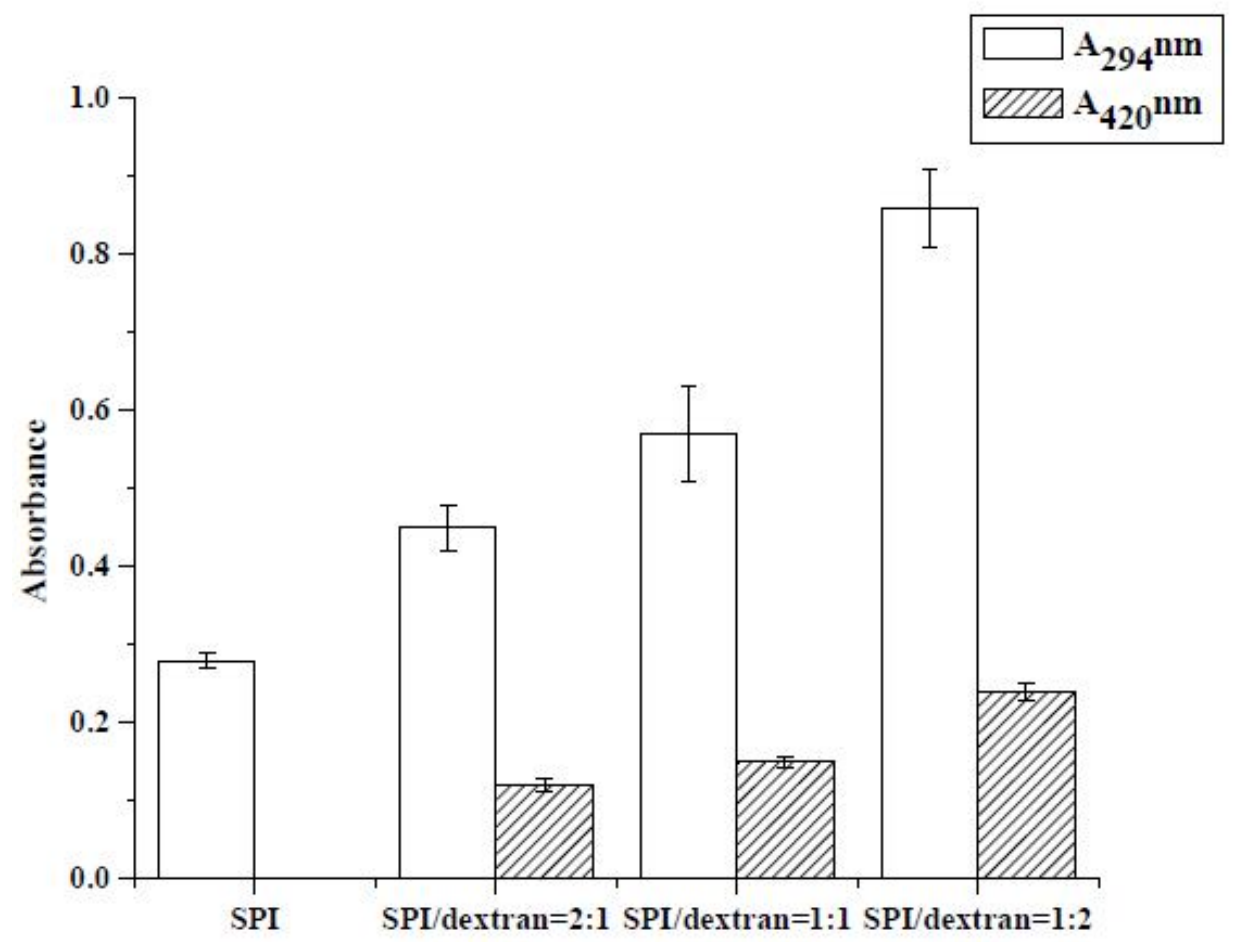

Figure 1: Absorbance wavelength $\left(A_{294}\right)$ and browning intensity. Data with different lowercase letters in the same test are significantly $(p<0.05)$ different 


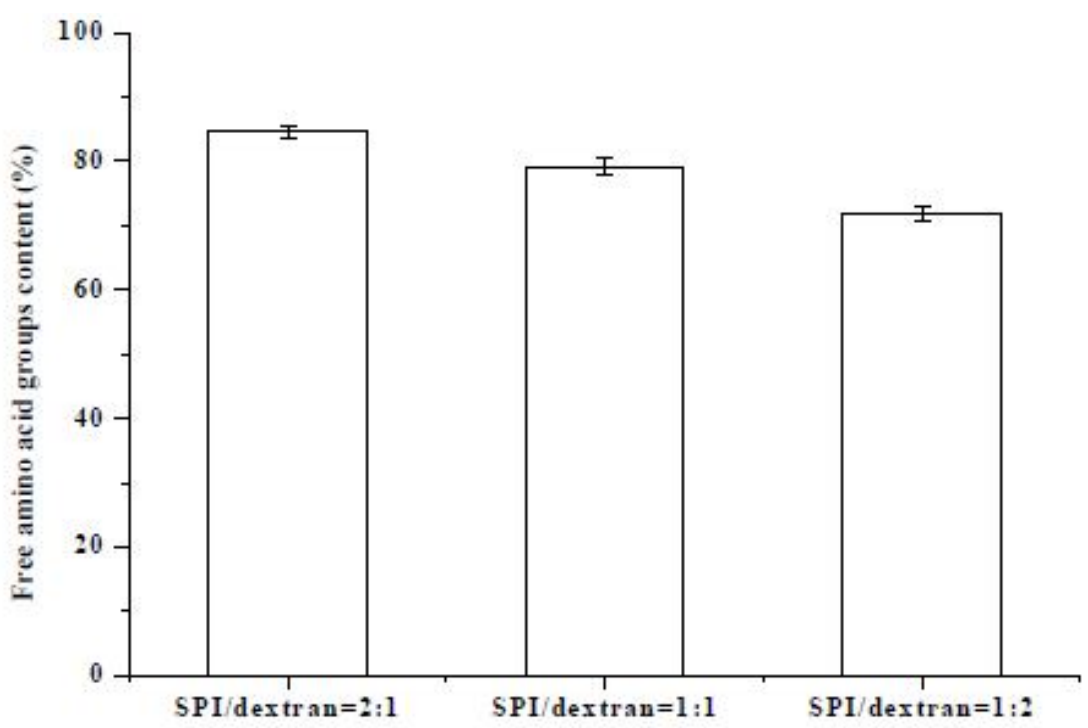

Figure 2: The free amino groups content of SPI-dextran glyconjugates The data with different lowercase letters in the same test are significantly $(p<0.05)$ different

\section{Particle size and zeta potential of SPI-dextran} nanoparticles

The sizes of the nanoparticles formed with SPI and SPI-dextran conjugation in the presence of different concentrations of $\mathrm{CaCl}_{2}$ were compared in Fig 3. At $\mathrm{CaCl}_{2}$ concentrations of 0 and 0.2 $\mathrm{mg} / \mathrm{mL}$, the average sizes of SPI were 100.2 and $387.6 \mathrm{~nm}$, respectively. Further addition of $\mathrm{CaCl}_{2}$ induced the precipitation of the particles. For the $\mathrm{SPI} /$ dextran complexes, they formed nanoparticles with similar sizes in the presence of $0-0.2 \mathrm{mg} / \mathrm{mL} \mathrm{CaCl}$. These values continued to increase until precipitation occurred at a threshold $\mathrm{CaCl}_{2}$ concentration, which varied with the mixing ratio. It was also noteworthy that the particle size tended to decrease with decreasing SPI/dextran mass ratio. Similar results have been reported on SPI-carboxymethyl chitosan complex nanoparticles [8].

The effect of dextran conjugation on the zeta potential of SPI nanoparticle dispersions was displayed in Figure 4. SPI exhibited a zeta potential of $-25.4 \mathrm{mV}$ and all of the SPI-dextran complexes were negatively charged. When $\mathrm{CaCl}_{2}$ was introduced into the dispersion, the zeta potential decreased gradually (in terms of its absolute value, same hereinafter). At the $\mathrm{CaCl}_{2}$ concentration of $0.2-1.6 \mathrm{mg} / \mathrm{mL}$, the zeta potential became more negative as the $\mathrm{SPI} /$ dextran mass ratio decreased and the particles formed with a SPI/dextran ratio of $1: 2$ exhibited a highest zeta potential.

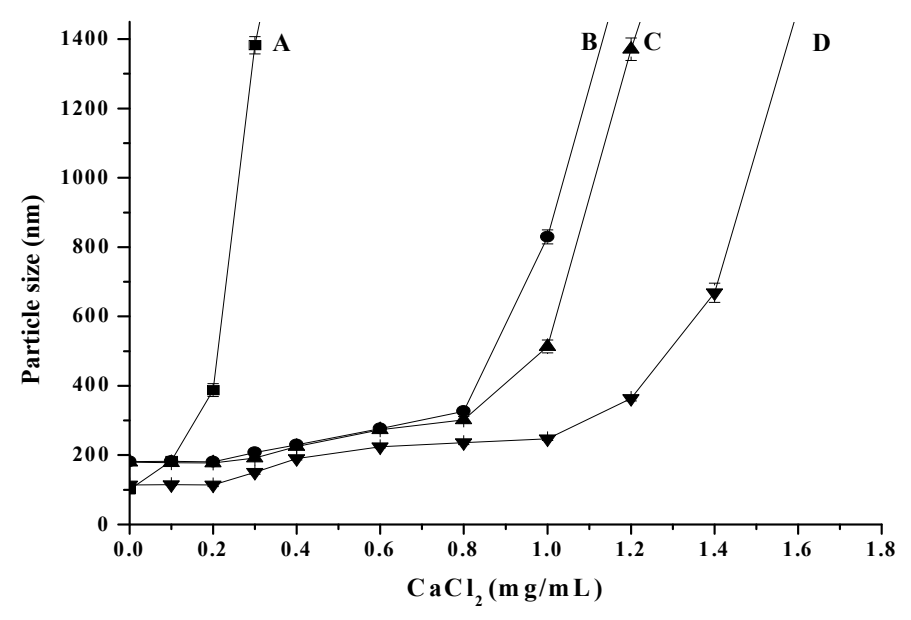

Figure 3: Effect of $\mathrm{CaCl}_{2}$ concentrations on the size of SPI and SPI-dextran nanoparticles. (A-SPI, B$\mathrm{SPI} /$ dextran=2:1, C-SPI/dextran=1:1, D-SPI/dextran=1:2). The data with different lowercase letters in the same test are significantly $(p<0.05)$ different 


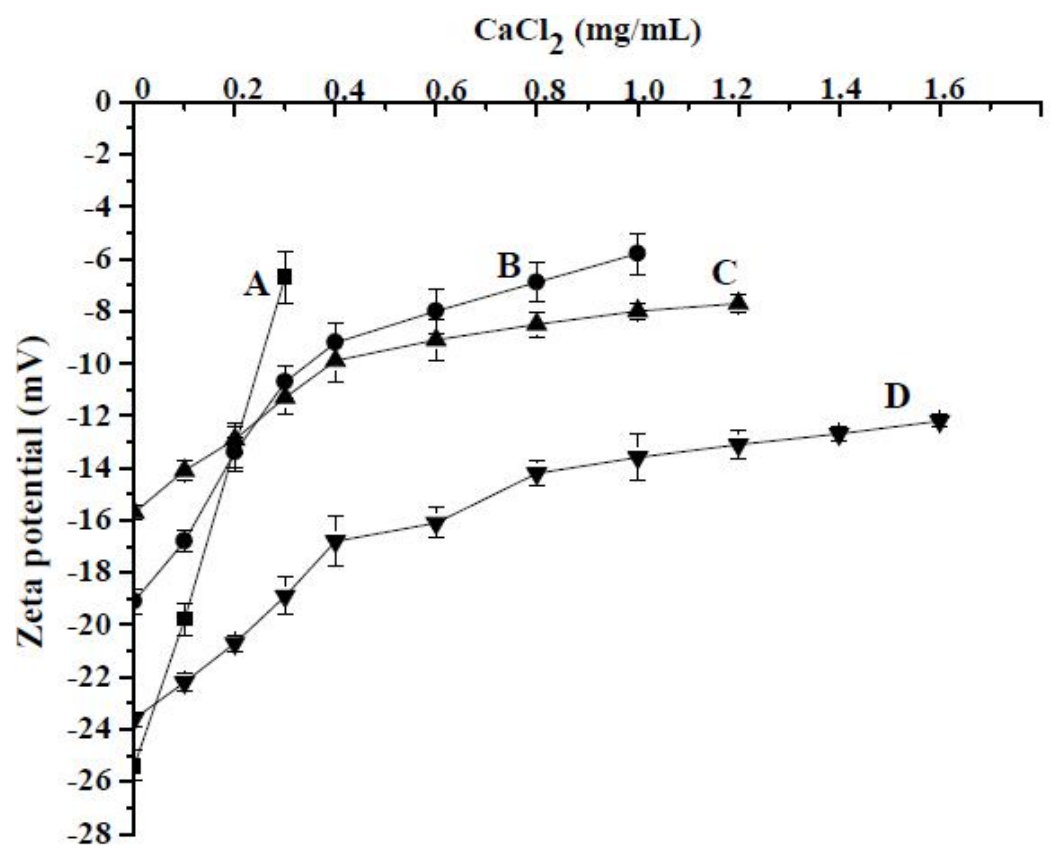

Figure 4: Effect of $\mathrm{CaCl}_{2}$ concentrations on the zeta potential of SPI and SPI/dextran nanoparticles; (A-SPI, B$\mathrm{SPI} /$ dextran $=2: 1, \mathrm{C}-\mathrm{SPI} /$ dextran $=1: 1, \mathrm{D}-\mathrm{SPI} /$ dextran $=1: 2)$. The data with different lowercase letters in the same test are significantly $(p<0.05)$ different

\section{Characteristics of theophylline-loaded nanoparticles}

Table 1 summarised the particle sizes, zeta potentials, encapsulation efficiencies (EE) and loading efficiencies (LE) of the theophyllineloaded nanoparticles. The sizes of dextran conjugated SPI nanoparticles were significantly greater than those of SPI, and they increased from 175.3 to $276.4 \mathrm{~nm}$ with increasing conjugation. On the other hand, there was no significant difference in the zeta potentials of the empty and theophylline-loaded nanoparticles. As for the SPI-dextran nanoparticles, they exhibited higher EE than SPI nanoparticles. In addition, increased ratio of dextran resulted in increased EE. A highest EE of $91.6 \%$ was achieved with the nanoparticles formed with a SPI/dextran mass ratio of $1: 2$, a theophylline/polymer mass ratio of $1: 10$ and a $\mathrm{CaCl}_{2}$ concentration of 0.8 $\mathrm{mg} / \mathrm{mL} \mathrm{CaCl} 2$. However, the overall LE of the $\mathrm{SPI} /$ dextran nanoparticles was only $8 \%$ higher than that achieved by SPI.

\section{Morphology of nanoparticles}

The morphology of nanoparticles formed with different formulas was compared in Fig 5. All of the prepared nanoparticles exhibited an approximate spherical shape and a rough surface (Fig. $5 \mathrm{~A}-\mathrm{C}$ ). The size varied from 150 to $250 \mathrm{~nm}$, which was consistent with the data from DLS study. The SPI/dextran mass ratio did not show any significant influence on the size and shape of the particles under SEM; therefore, only one representative image for complex nanoparticle formed with a SPI/dextran mass ratio of 1:1 (Figure 5B) and one for control SPI (Figure 5A) were shown. When theophylline was incorporated, the particles maintained their spherical structure, although some of them were observed to approach each other and form denser clusters (Figure 5C). Similar results were reported on conjugated SPI nanoparticles by Teng et al [19].

Table 1: Characteristics of theophylline-loaded SPI and SPI/dextran nanoparticles

\begin{tabular}{lcccc}
\hline Sample & Particle size $(\mathbf{n m})$ & Zeta potential $(\mathbf{m V})$ & EE \% & LE \% \\
\hline SPI & $161.6 \pm 6.7^{\mathrm{c}}$ & $-18.64 \pm 0.39^{\mathrm{a}}$ & $51.8 \pm 1.2^{\mathrm{c}}$ & $2.99 \pm 0.17^{\mathrm{c}}$ \\
SPI/dextran=2:1 & $175.3 \pm 5.8^{\mathrm{c}}$ & $-18.7 \pm 0.58^{\mathrm{ab}}$ & $83.4 \pm 2.5^{\mathrm{b}}$ & $3.25 \pm 0.08^{\mathrm{a}}$ \\
SPI/dextran=1:1 & $237.2 \pm 7.3^{\mathrm{b}}$ & $-22.25 \pm 0.25^{\mathrm{b}}$ & $89.8 \pm 3.5^{\mathrm{a}}$ & $3.15 \pm 0.12 \mathrm{a}^{\mathrm{b}}$ \\
SPI/dextran=1:2 & $276.4 \pm 7.5^{\mathrm{a}}$ & $-24.97 \pm 0.78^{\mathrm{a}}$ & $91.6 \pm 2.1^{\mathrm{a}}$ & $3.08 \pm 0.24^{\mathrm{b}}$ \\
\hline
\end{tabular}

Data with different letters indicate significant difference $(n=3, p<0.05)$ 

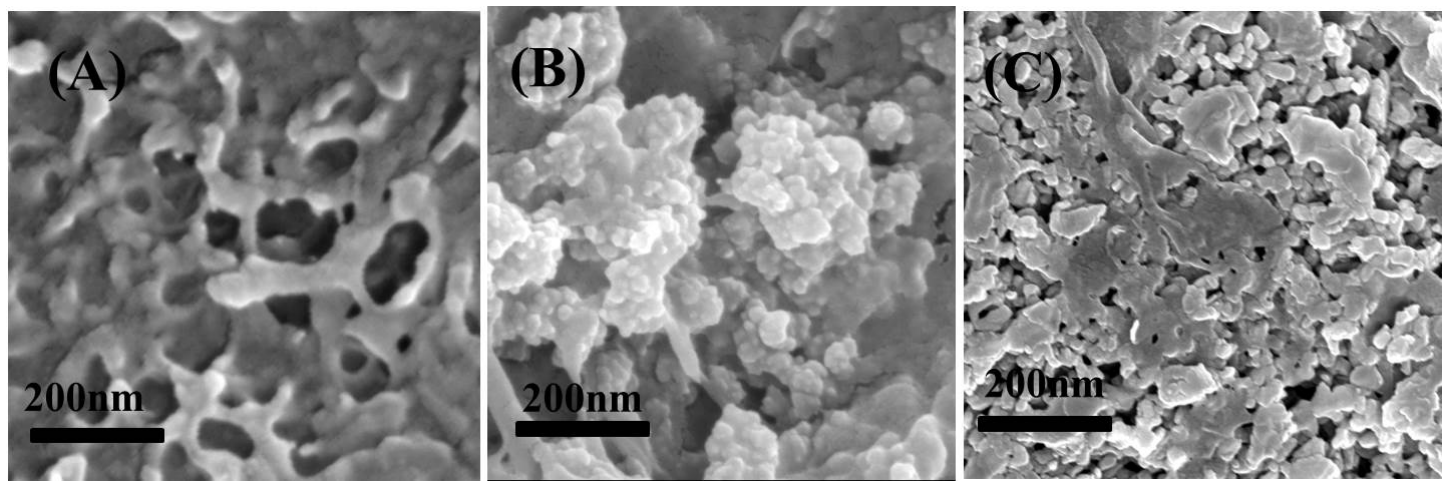

Figure 5: SEM-analysis of SPI (A), SPI-dextran (B) and theophylline-loaded SPI/dextran (C) nanoparticles

\section{FT-IR spectra}

As shown in Fig 6, a major band at $3299 \mathrm{~cm}^{-1}$ was observed in the spectra of SPI. This peak was denoted to the stretching of hydrogenbonded $\mathrm{O}-\mathrm{H}$ groups. Meanwhile, SPI nanoparticles exhibited two characteristic bands at 1649 (amide I, C=O stretching) and $1535 \mathrm{~cm}^{-1}$ (amide II, N-H bending). For carbohydrates, a series of overlapping peaks located in the region of $1180-953 \mathrm{~cm}^{-1}$ results from vibration modes such as the stretching of $\mathrm{C}-\mathrm{C}$ and $\mathrm{C}-\mathrm{O}$ and the bending mode of $\mathrm{C}-\mathrm{H}$ bonds. These are often referred to as the "saccharide" bands and are the most intense bands in the mid-infrared spectrum. These absorptions are weak in the spectra of most proteins [15]. As can be seen in Fig. 6, the absorptions in the region of 1180-953 $\mathrm{cm}^{-1}$ were stronger in SPI-dextran than in SPI and weaker than dextran. Regions of 1650 and $1540 \mathrm{~cm}^{-1}$, referred to as $\mathrm{C}=\mathrm{O}$ and $\mathrm{C}-\mathrm{N}$ stretching from amide I and II, were modified by the glycation, because the intensity of SPIdextran decreased compared to SPI. In proteins, there is an amide III band at $1300-1200 \mathrm{~cm}^{-1}$. This band is known to be very complex and mainly arises from $\mathrm{C}-\mathrm{N}$ stretching and $\mathrm{N}-\mathrm{H}$ deformation. The entire spectral features of the amide III band for the SPI-dextran (Fig. 6) showed a decrease in intensity compared to SPI. The above results indicated that there seemed to be a dextran attached to the SPI.

\section{Release of theophylline}

The releasing profiles of theophylline-loaded nanoparticles were depicted in Fig. 7. After incubation at $37^{\circ} \mathrm{C}$ in simulated gastric fluid for $30 \mathrm{~min}$, over $43 \%$ of the theophylline was released from the SPI nanoparticles.

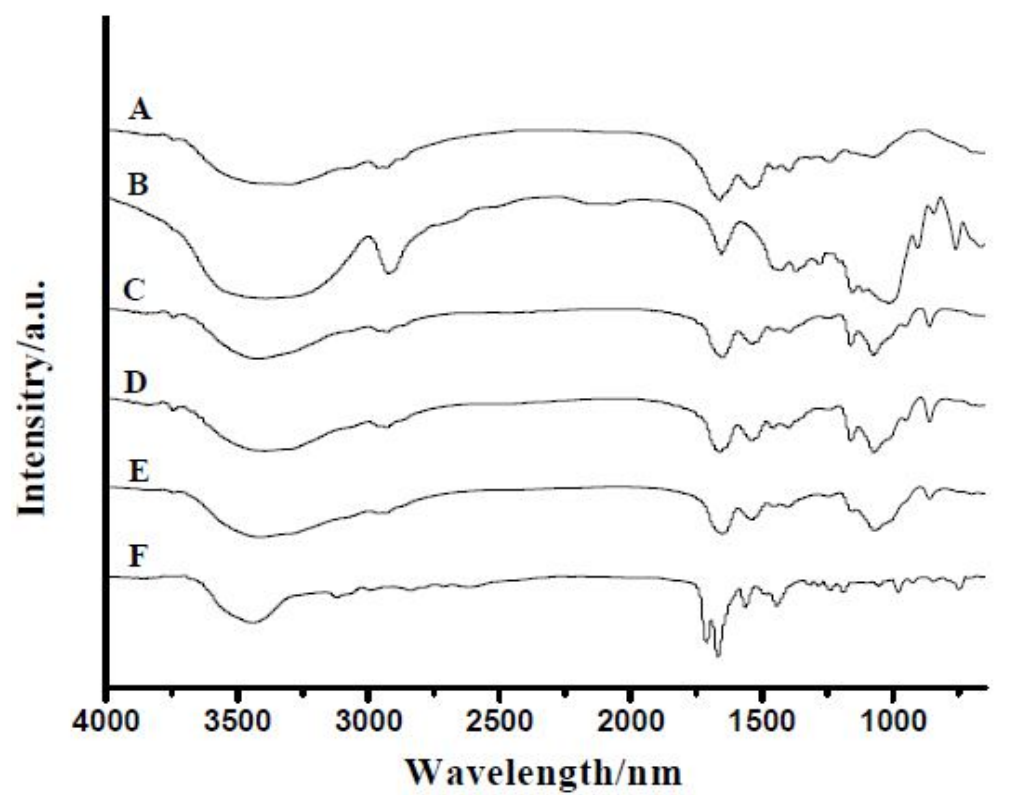

Figure 6: FT-IR spectra of empty SPI nanoparticle (A), dextran (B), SPI-dextran conjugate (C), theophyllineloaded SPI nanoparticle (D), theophylline-loaded SPI-dextran nanoparticle (E) and theophylline (F) 


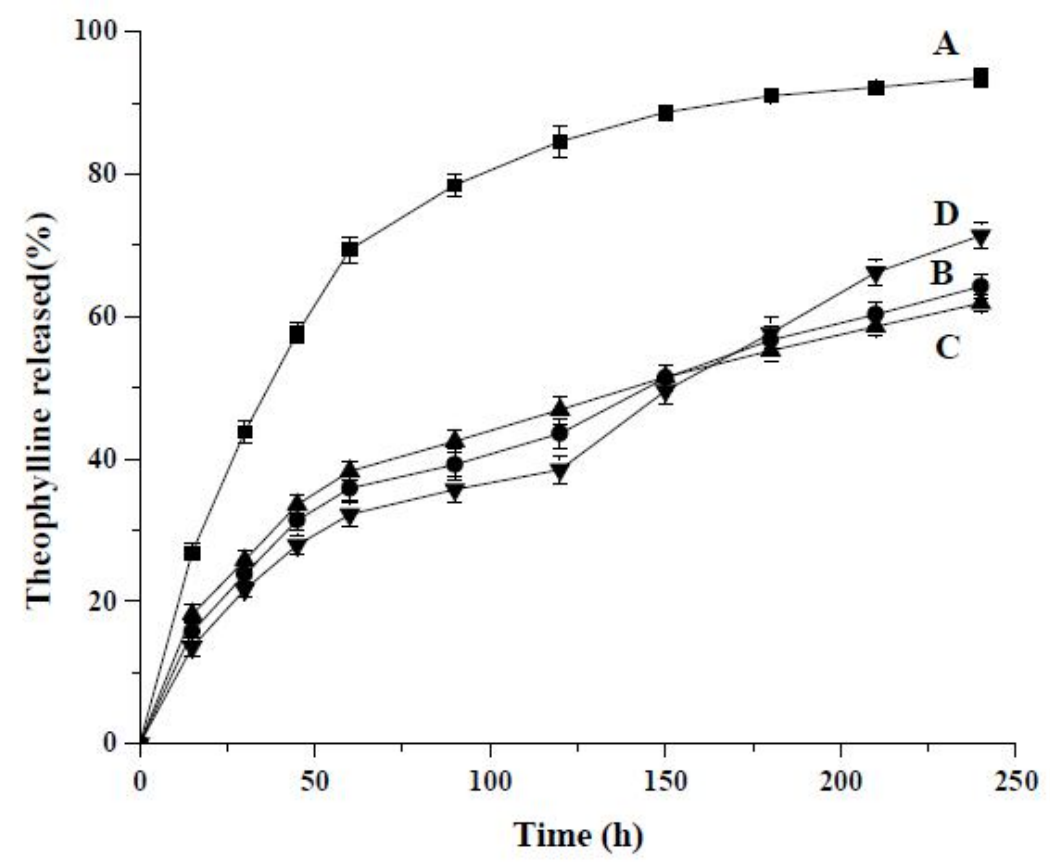

Figure 7: Release of theophylline in simulated gastric and intestinal fluid from SPI and SPI-dextran nanoparticles. (A-SPI; B-SPI/dextran=1:1; C-SPI/dextran=2:1; D-SPI/dextran=1:2). The data with different lowercase letters in the same test are significantly $(p<0.05)$ different

In contrast, less than $26 \%$ of the theophylline was detected in the releasing medium containing SPI-dextran nanoparticles. Riche and Williams [6] also found that the polymeric matrix formed with SPI was highly digestible by pepsin. When transferred to the simulated intestinal fluid $(\mathrm{pH}$ 7.4), the samples containing dextran became negatively charged and therefore soluble. As a result, at most $71 \%$ of the remaining theophylline was released from the polymeric matrix in the following $2 \mathrm{~h}$. In addition, among the three tested complex formulas, the one with a dextran:SPI mass ratio of 1:2 resulted in a least amount of released theophylline.

\section{DISCUSSION}

SPI-dextran conjugate was synthesized successfully by a $\mathrm{TiO}_{2}$ photocatalyzed method, which was evidenced by UV-vis absorption, free amino group and FT-IR analysis. Higher increase in $\mathrm{A}_{294}$ after $\mathrm{TiO}_{2}$ photocatalysis treatment, comparing to increase in $A_{420}$, suggests the domination of the early stage of the Maillard reaction under applied conditions. Free amino group results further indicate that dextran was conjugated to SPI via a chemical linkage to the free amino groups. To strengthen the conjugation of SPI and dextran, FT-IR analysis was used to confirm their glycation.

The SPI-dextran conjugate was further used to prepare the complex nanoparticle. The particle size and zeta potential results indicate that a larger quantity of nanoparticles with smaller size can be formed by complexation of dextran with SPI. When SPI was grafted with dextran molecules, part of its primary amino groups lost their positive charges after they formed covalent bonds with dextran backbone, resulting in a higher hydrophobicity of the soy protein molecules. In addition, the amino and hydroxyl groups on the pteridine ring could provide additional hydrogen-bonding, if appropriate orientation was allowed. Both of these changes facilitated the aggregation of SPI into nanoparticles [19].

Furthermore, as can be seen in Table 1, SPIdextran nanoparticles exhibited higher EE and LE than SPI ones, suggesting that SPI-dextran nanoparticles possessed a more compact structure, with more functional groups involved in the polymer-theophylline interaction. It was also suggested from the results that a larger number of SPI-dextran molecules were involved in particle formation and theophylline encapsulation than nonconjugated SPI, which allowed a stronger protein- theophylline interaction and thus resulted in higher EE and LE.

FT-IR results show that the bands appearing at 1711 and $1668 \mathrm{~cm}^{-1}$ assigned to -CO-N(R)-COtheophylline characteristic group were not detected in the spectra of theophylline-loaded nanoparticles. The disappearance of these characteristic peaks indicated successful 
encapsulation of theophylline in the polymeric matrix. The peaks corresponding to $\mathrm{O}-\mathrm{H}$ stretch in the spectra of theophylline-loaded nanoparticles showed an increase in intensity compared to those for the empty nanoparticles. In the meantime, the position of these peaks shifted to higher wavenumbers. These differences suggested increased involvement of hydrogen bonding, especially in the hydroxyl groups [20], probably with the incorporated theophylline. Finally, based on the results of control release, SPI-dextran complex nanoparticles demonstrated prominent protection on theophylline against digestion in the gastric fluid, together with an increased amount of theophylline being delivered to the small intestine, in comparison with the nanoparticles formed with SPI.

\section{CONCLUSION}

SPI-dextran conjugate has been synthesized successfully by a $\mathrm{TiO}_{2}$ photocatalyzed method and is suitable as a nanoencapsulant for delivery of theophylline. The synthesized nanoparticles exhibit higher EE and LE, as well as superior controlled drug release. Thus, the synthesized nanoparticle approach is potentially a suitable method for the encapsulation and controlled release of drugs and, possibly, nutraceuticals.

\section{ACKNOWLEDGEMENT}

The authors are grateful for the financial support from Non-Funding Programs for Science and Technology Development of Zhanjiang (no. 2013B01053) and Open Project Program of Process of Starch and Vegetable Protein Engineering Research Center of Ministry of Education (no. 2013-ERC-01), and China Spark Program (no. 2014GA780072).

\section{REFERENCES}

1. Oprea AM, Nistor MT, Popa MI, Lupusoru CE, Vasile C. In vitro and in vivo theophylline release from cellulose/chondroitin sulfate hydrogels. Carbohyd Polym 2012; 90: 127-133.

2. Jahanshahi M, Babaei Z. Protein nanoparticle: $A$ unique system as drug delivery vehicles. Afr J Biotechnol 2008; 7: 4926-4934.

3. Naahidi $S$, Jafari $M$, Edalat $F$, Raymond $K$, Khademhosseini A, Chen P. Biocompatibility of engineered nanoparticles for drug delivery. J Control Release 2013; 166: 182-194.

4. Kawashim Y. Preface nanoparticulate systems for improved drug delivery. Adv Drug Deliver Rev 2001; 47: 1-2.
5. Weber C, Coester C, Kreuter J, Langer K. Desolvation process and surface characterisation of protein nanoparticles. Int J Pharm 2000; 194: 91-102.

6. Riche M, Williams TN. Apparent digestible protein, energy and amino acid availability of three plant proteins in Florida pompano, Trachinotus carolinus $L$. in seawater and low-salinity water. Aquacult Nutr 2010; 16: 223-230.

7. Teng Z, Luo YC, Wang Q. Nanoparticles synthesized from soy protein: Preparation, characterization, and application for nutraceutical encapsulation. J Agric Food Chem 2012; 60: 2712-2720.

8. Teng Z, Luo YC, Wang Q. Carboxymethyl chitosan-soy protein complex nanoparticles for the encapsulation and controlled release of vitamin D3. Food Chem 2013; 141: 524-532.

9. Aumelas A, Serrero A, Durand A, Dellacherie E, Léonard M. Nanoparticles of hydrophobically modified dextrans as potential drug carrier systems. Colloid Surface B 2007; 59: 74-80.

10. Broaders KE, Grandhe S, Fréchet JMJ. A biocompatible oxidation-triggered carrier polymer with potential in therapeutics. J Am Chem Soc 2011; 133: 756-758.

11. Ide $Y$, Nakamura $N$, Hattori $H$, Ogino $R$, Ogawa $M$, Sadakane $M$, Sano $T$. Sunlight-induced efficient and selective photocatalytic benzene oxidation on $\mathrm{TiO}_{2}$ supported gold nanoparticles under $\mathrm{CO}_{2}$ atmosphere. Chem Commun 2011; 47: 11531-11533.

12. Lang XJ, Ma WH, Zhao YB, Chen CC, Ji HW, Zhao JC. Visible-Light-Induced Selective Photocatalytic Aerobic Oxidation of Amines into Imines on $\mathrm{TiO}_{2}$. Chemistry 2012; 18: 2624-2631.

13. Chong RF, Li J, Zhou X, Ma Y, Yang JX, Huang L, Han H $X$, Zhang $F X, L i$ C. Selective photocatalytic conversion of glycerol to hydroxyacetaldehyde in aqueous solution on facet tuned $\mathrm{TiO}_{2}$-based catalysts. Chem Commun 2014; 50: 165-167.

14. Boyapally $H$, Nukala RK, Bhujbal P, Douroumis $D$. Controlled release from directly compressible theophylline buccal tablets. Colloid Surface B 2010; 77: 227-233.

15. Caillard R, Remondetto GE, Subirade $M$. Physicochemical properties and microstructure of soy protein hydrogels co-induced by Maillard type crosslinking and salts. Food Res Int 2009; 42: 98106.

16. Zhang J, Liang L, Tian Z, Chen L, Subirade $M$. Preparation and in vitro evaluation of calcium-induced soy protein isolate nanoparticles and their formation mechanism study. Food Chem 2012; 133: 390-399.

17. Luo Y, Teng Z, Wang Q. Development of zein nanoparticles coated with carboxymethyl chitosan for encapsulation and controlled release of vitamin D3. J Agric Food Chem 2012; 60: 836-843.

18. Zhang X, Qi JR, Li KK, Yin SW, Wang JM, Zhu JH, Yang $X Q$. Characterization of soy $\beta$-conglycinin-dextran conjugate prepared by Maillard reaction in crowded liquid system. Food Res Int 2012; 49: 648-654.

Trop J Pharm Res, August 2015; 14(8): 1331 
Jin et al

19. Teng Z, Luo YC, Wang $T$, Zhang B, Wang $Q$. Development and Application of Nanoparticles Synthesized with Folic Acid Conjugated Soy Protein. J Agric Food Chem 2013; 61: 2556-2564.
20. Luo Y, Zhang B, Whent M, Yu L, Wang Q. Preparation and characterization of zein/chitosan complex for encapsulation of $\alpha$-tocopherol, and its in vitro controlled release study. Colloid Surface B 2011; 85: 145-152. 